\title{
PENGUKURAN EFEKIVITAS IKLAN GOJEK MENGGUNAKAN METODE EPIC MODEL DI KALANGAN MAHASISWA
}

\author{
Azri Wajihan Mahdi \\ Universitas Pembangunan Nasional Veteran Jakarta \\ azri.wajihan@upnvj.ac.id \\ Diana Triwardhani \\ Universitas Pembangunan Nasional Veteran Jakarta \\ dient_upn@yahoo.com \\ Heni Nastiti \\ Universitas Pembangunan Nasional Veteran Jakarta \\ heni_nastiti@yahoo.com
}

\begin{abstract}
This research is a descriptive quantitative study that aims to find out how effective Gojek's online advertising is for students living in Jakarta using the EPIC Model method. The sample in this study used 100 active students residing in Jakarta as respondents. Sample selection was done by purposive sampling method with non-probability sampling technique. In this study, measurements will be carried out on the 4 dimensions of EPIC by looking for the average score of each dimension, the results of the study show the empathy dimension with an average value of 3.81 which makes advertising able to attract customers' attention, the dimension of persuasion with an average value of 4.05 which means that advertising can affect customers, the impact dimension with an average value of 3.75 which makes the advertisement give a deep impression to the customer, and the communication dimension with an average value of 4.11 which can be stated that Gojek advertising can be well remembered and understood. From the results of the EPIC Rate of the four dimensions, the average EPIC score of 3.93 indicates the effective category.
\end{abstract}

Keywords: advertisement, advertising effectiveness, EPIC Model

\section{PENDAHULUAN}

Selama berlangsungnya pandemi, keadaan ekonomi seluruh dunia mengalami penurunan, Indonesia pun juga mengalami penurunan pertumbuhan ekonomi pada tahun 2020 hingga minus 2\% (Santoso, 2020). Gojek saat ini telah menjadi super apps dengan menyediakan 20 layanan berbeda dalam aplikasinya serta memiliki lebih dari 20 juta mitra yang berbeda dan 900 ribu mitra merchant yang menjadikan Gojek sebagai salah satu perusahaan transportasi online terbesar di Indonesia dengan lebih dari 38 juta pengguna aktif di Asia Tenggara (Ludwianto, 2020). Di Indonesia, Gojek bersaing dengan Grab sebagai penyedia layanan transportasi online, namun berhasil mengungguli Grab, pesaingnya, dalam pasar transportasi online dengan perbandingan pasar yaitu Gojek 36\%, Grab 32\%, dan 
sisa sebesar 32\% merupakan pengguna aplikasi tersebut (IndoTelko, 2019). Dengan adanya pandemi, Gojek memutar strateginya untuk membuat sebuah kampanye dan program, yaitu kampanye \#dirumahaja agar masyarakat tidak perlu keluar rumah ataupun mengurangi kegiatannya untuk berada diluar rumah selama pandemi ini berlangsung, ada juga program J3K yang memiliki kepanjangan jaga kesehatan, jaga kebersihan, dan jaga keamanan yaitu sebuah program Gojek untuk menjaga kualitas layanannya pada masa pandemi seperti ini (Gojek, 2020). Promosi kampanye serta program tersebut membuahkan hasil, karena terjadi pertumbuhan transaksi sebesar $10 \%$ serta kenaikan penggunaan Gopay sebanyak 2 kali lipat pada masa pandemi ini, hal tersebut terjadi karena adanya dorongan berbelanja online diantara masyarakat (Burhan, 2020).

Dalam melakukan promosi atau periklanan yang efektif, perusahaan sering menggunakan rasa emosional untuk memperdalam komunikasi iklan dan hubungan merk yang dimiliki dengan tiap konsumennya. Cerita yang emosional dalam melakukan promosi lebih dapat diterima baik oleh masyarakat, dengan rasa emosional tersebut diharapkan akan menumbuhkan keterikatan hubungan antara iklan dengan masyarakat yang melihat. Buktinya Gojek mendapatkan penghargaan Most Loved Indonesian Ramadhan Ad pada tahun 2019 yang menunjukan bahwa iklan Gojek dapat menyentuh perasaan emosional bagi masyarakat yang melihatnya (Aryanto, 2019). Berdasarkan fenomena iklan-iklan tersebut dapat diasumsikan bahwa iklan Gojek dapat memengaruhi perasaan emosi yang mencakup keempat dimensi dari EPIC Model yaitu empati, persuasi, dampak, dan komunikasi untuk mengetahui efektivitas dari promosi yang telah dilakukan oleh Gojek. Dalam keempat dimensi EPIC tersebut masing-maisng dimensi memengaruhi respon afeksi, kognisi, ketertarikan terhadap iklan, perilaku serta sikap pelanggan pasca melihat iklan, keunikan iklan yang membuat iklan lebih menonjol dari iklan pesaing yang membuat masyarakat yang telah melihat iklan tersebut menjadi suka untuk mengulang iklan tersebut, dan bagaimana kemampuan masyarakat yang telah melihat iklan untuk dapat mengingat serta memahami pesan dari iklan.

Dalam melakukan suatu periklanan, efektivitas dari iklan tersebut penting untuk mengetahui apakah komunikasi dari iklan tersebut dapat tersampaikan ke masyarakat yang telah melihat iklan, jadi berdasarkan penjelasan mengenai iklan Gojek sebelumnya penulis ingin mengetahui seberapa efektif periklanan online yang telah dilakukan oleh Gojek. Adapun tujuan dari penelitian ini adalah untuk mengukur seberapa efektif iklan online Gojek dengan menggunakan metode EPIC Model untuk mengukur efektivtias iklannya.

\section{KAJIAN PUSTAKA Periklanan}

Dalam penelitian ini akan menjelaskan mengenai periklanan yang memiliki peran penting dalam berjalannya kegiatan perusahaan sebagai penyebar informasi 
kepada msayarakat karena dengan periklanan yang efektif dapat meningkatkan penjualan jasa atau produk perusahaan. Periklanan menurut Morrisan dalam penelitian (Indah \& Maulida, 2017) adalah bentuk komunikasi non-personal mengenai suatu produk, jasa, ide, atau organisasi yang telah dibayar oleh suatu usaha atau sponsor tertentu. Prisgunanto dalam penelitian (Gisrang, 2017) berpendapat bahwa iklan berisi mengenai perang informasi yang berusaha untuk memengaruhi sikap beli dan pengarahan pada perilaku konsumen.

Hermawan dalam (Pancaningrum \& Sari, 2019) menyatakan bahwa periklanan adalah suatu penyajian dan promosi atas ide-ide produk atau jasa yang dilakukan oleh suatu perusahaan tertentu. Selanjutnya, menurut (Sastika, 2018) periklanan merupakan proses komunikasi massa yang melibatkan sponsor tertentu untuk pemasangan iklan dengan membayar sebuah jasa media massa atas penyiaran iklannya. Menurut Philip Kotler dalam (Amira \& Nurhayati, 2019) menyatakan bahwa tujuan iklan dibagai atas iklan informative, persuasive, dan reminding. Sedangkan menurut Kasali dalam (Indrawati, Sudiarta, \& Suardana, 2017) periklanan adalah bagian dari bauran pemasaran yang dapat dikatakan sebagai pesan untuk menawarkan suatu produk atau jasa ke masyarakat.

\section{Efektivitas Iklan}

Efektivitas iklan menurut Effendy dalam (Bestriandita \& Widodo, 2017) adalah kondisi seberapa jauh efek iklan dapat menarik perhatian, dimengerti, diingat, membangkitkan emosi, dan menggerakan sasarannya untuk memberikan tanggapan yang di kehendaki oleh pengiklan. Menurut Wells dalam (Gunawan, 2015) iklan yang efektif bekerja pada 2 tingkatan, yang pertama iklan harus dapat memuaskan tujuan konsumen dengan menciptakan ikatan dengan konsumen serta menyampaikan pesan yang relevan dan yang kedua iklan harus mencapai tujuan dari pengiklan. Menurut Durianto dalam (Reyes, Serafico, Hendrayati, \& Ramdhan, 2019) efektivitas iklan dapat diukur dengan menggunakan EPIC Model dengan mengukur keempat dimensinya. Shimp dan Andrews dalam (Erminati Pancaningrum \& Wahyu Ari Rahayu, 2017) ada kriteria agar iklan dapat dikatakan efektif, yaitu:

1. Periklanan harus sesuai dengan strategi pemasaran.

2. Iklan yang efektif harus memiliki sudut pandang kosumen.

3. Iklan harus unik agar dapat menarik perhatian.

4. Iklan harus sesuai dengan kenyataan dan tidak di lebih-lebihkan.

5. Mencegah ide kreatif yang membuat strategi menjadi tidak jelas.

EPIC Model merupakan salah satu alat untuk mengukur efektivtias iklan dengan pendekatan komunikasi. Menurut (Putro, 2017) komunikasi adalah suatu proses penyampaian informasi untuk mencapai pengertian yang sama antar komunikator dengan komunikan agar mampu tercapainya tujuan komunikasi. Jika 
EPIC Model disambungkan dengan komunikasi maka komunikasi penting untuk periklanan agar masyarakat yang melihat iklan dapat mengerti pesan iklan demi tercapainya tujuan pengiklanan.

\section{EPIC Model}

AC Nielsen merupakan sebuah perusahaan sekaligus penggagas EPIC Model untuk dijadikan sebagai pengukur suatu efektivitas iklan. EPIC Model memiliki 4 dimensi yang masing-masingnya adalah empati, persuasi, dampak, dan komunikasi (Putra, Noviyanto, \& Christover, 2018). Berikut merupakan penjelasan EPIC Model berdasarakan dari AC Nielsen dalam (Erminati Pancaningrum \& Wahyu Ari Rahayu, 2017):

1. Dimensi empati, adalah dimensi yang menginformasikan apakah konsumen suka terhadap iklan yang ditampilkan untuk melihat hubungan antara iklan dengan konsumen.

2. Dimensi persuasi, adalah dimensi yang menginformasikan apa yang akan dberikan iklan tersebut untuk mengembangkan dan menguatkan karakter dari sebuah brand.

3. Dimensi dampak, merupakan dampak yang diberikan oleh iklan tersebut kepada konsumen, bisa dilihat dari ketertarikan konsumen ataupun pengetahuan produk yang diketahui oleh konsumen.

4. Dimensi komunikasi, dimensi yang menyediakan informasi mengenai kemampuan konsumen untuk mengingat dan memahami pesan dari iklan.

Selain itu, ada juga pengertian dari Durianto dalam penelitian (Purwanto, Ade dan umam, 2019) mengenai EPIC Model yang serupa dengan AC Nielsen, yaitu:

1. Dimensi empati, mengenai keadaan mental seseorang yang membuatnya dapat mengidentifikasi perasaan pada dirinya maupun orang lain, dalam dimensi ini akan melibatkan afeksi dan kognisi untuk mengetahui respon emosional seseorang terhadap suatu iklan.

2. Dimensi persuasi, merupakan perubahan dari sikap, perilaku, kepercayaan, dan keinginan dari konsumen sebagai akibat dari suatu komunikasi dari suatu iklan, mengenai apakah iklan dapat memengeruhi keputusan pembelian konsumen terhadap produk atau jasa yang diiklankan.

3. Dimensi dampak, dilihat dari apakah iklan dapat lebih menonjol dari iklan pesaing dari kategori usaha yang sama serta apakah iklan dapat terlihat lebih menarik dimata konsumen dari pada iklan pesaingnya.

4. Dimensi komunikasi, dimensi ini memberikan informasi seberapa baik konsumen dapat mengingat pesan utama iklan, pemahaman dari iklan, dan kesan konsumen terhadap iklan. 


\section{METODOLOGI PENELITIAN}

Penelitian ini dilakukan di Jakarta kepada 100 responden dengan kriteria: 1) mahasiswa aktif yang bertempat tinggal di Jakarta, 2) pernah melihat iklan online Gojek di media online manapun. Sumber data adalah primer karena akan didapat dari jawaban responden atas kuesioner yang akan dibagikan melalui online dengan bantuan Google Form dengan skala yang dipakai adalah skala likert dengan rentang nilai yaitu 1 hingga 5 yang menunjukan nilai dari sangat tidak setuju hingga sangat setuju. Data kuantitatif akan dikelola dengan beberapa proses. Yang pertama akan di lakukan uji validitas dan uji reabilitas terhadap data yang telah diperoleh lalu akan dilakukan analisis tabulasi sederhana untuk mengubah data ke dalam bentuk persentase, mencari rentang skala nilai EPIC, dan perhitungan rata-rata terhadap jawaban dari responden. Untuk melakukan perhitung data akan digunakan software SPSS versi 25.

\section{HASIL DAN PEMBAHASAN}

\section{Uji Validitas}

Data dapat dikatakan valid apabila hasil dari $\mathrm{r}$ hitung lebih besar dari $\mathrm{r}$ tabel (Sugiyono, 2016).

1. Hasil uji validitas dimensi empati

\section{Tabel 1}

TABEL UJI VALIDITAS DIMENSI EMPATI

\begin{tabular}{ccc}
\hline Pertanyaan & $\begin{array}{c}\text { Pearson Correlation } \\
/ \\
\text { r hitung }\end{array}$ & R tabel \\
\hline $\mathrm{X} 1.1$ & 0,665 \\
\hline $\mathrm{X} 1.2$ & 0,475 \\
\hline $\mathrm{X} 1.3$ & 0,593 & \\
\hline $\mathrm{X} 1.4$ & 0,515 & \\
\hline $\mathrm{X} 1.5$ & 0,673 & 0,361 \\
\hline $\mathrm{X} 1.6$ & 0,713 \\
\hline $\mathrm{X} 1.7$ & 0,753 & \\
\hline $\mathrm{X} 1.8$ & 0,800 \\
\hline $\mathrm{X} 1.9$ & 0,749 \\
\hline
\end{tabular}

Berdasarkan tabel tersebut dapat dilihat bahwa semua instrumen dimensi empati dapat dinyatakan valid. 
2. Hasil uji validitas dimensi persuasi

Tabel 2.

TABEL UJI VALIDITAS DIMENSI PERSUASI

\begin{tabular}{ccc}
\hline Pertanyaan & $\begin{array}{c}\text { Pearson Correlation } \\
/ \\
\text { r hitung }\end{array}$ & R tabel \\
\hline $\mathrm{X} 2.1$ & 0,503 & \\
\hline $\mathrm{X} 2.2$ & 0,858 & \\
\hline $\mathrm{X} 2.3$ & 0,878 & 0,361 \\
\hline $\mathrm{X} 2.4$ & 0,874 & \\
\hline $\mathrm{X} 2.5$ & 0,941 & \\
\hline $\mathrm{X} 2.6$ & 0,815 & \\
\hline
\end{tabular}

Berdasarkan tabel tersebut dapat dilihat bahwa semua instrument dimensi persuasi dapat dinyatakan valid.

3. Hasil uji validitas dimensi dampak

Tabel 3.

TABEL UJI VALIDITAS DIMENSI DAMPAK

\begin{tabular}{ccc}
\hline Pertanyaan & $\begin{array}{c}\text { Pearson Correlation } \\
/ \\
\text { r hitung }\end{array}$ & R tabel \\
\hline $\mathrm{X} 3.1$ & 0,763 & \\
\hline $\mathrm{X} 3.2$ & 0,683 & \\
\hline $\mathrm{X} 3.3$ & 0,705 & 0,361 \\
\hline $\mathrm{X} 3.4$ & 0,831 & \\
\hline $\mathrm{X} 3.5$ & 0,810 & \\
\hline $\mathrm{X} 3.6$ & 0,757 & \\
\hline $\mathrm{X} 3.7$ & 0,852 & \\
\hline $\mathrm{X} 3.8$ & 0,620 & \\
\hline $\mathrm{X} 3.9$ & 0,763 &
\end{tabular}

Berdasarkan tabel tersebut dapat dilihat bahwa semua instrumen dimensi dampak dapat dinyatakan valid. 
4. Hasil uji validitas dimensi komunikasi

Tabel 4.

\section{UJI VALIDITAS DIMENSI KOMUNIKASI}

\begin{tabular}{ccc}
\hline Pertanyaan & $\begin{array}{c}\text { Pearson Correlation } \\
/ \\
\text { r hitung }\end{array}$ & R tabel \\
\hline $\mathrm{X} 4.1$ & 0,451 & \\
\hline $\mathrm{X} 4.2$ & 0,569 & \\
\hline $\mathrm{X} 4.3$ & 0,678 & 0,361 \\
\hline $\mathrm{X} 4.4$ & 0,427 & \\
\hline $\mathrm{X} 4.5$ & 0,768 & \\
\hline $\mathrm{X} 4.6$ & 0,806 & \\
\hline
\end{tabular}

Berdasarkan tabel tersebut dapat dilihat bahwa semua instrumen dimensi komunikasi dapat dinyatakan valid.

\section{Uji Reliabitias}

Dapat reliabel atau tidaknya suatu instrument akan dapat diketahui apabila hasil perhitungan uji reliabilitas lebih besar dari 0,60 dari nilai Cronbach's Alpha (Sugiyono, 2016).

Tabel 5.

HASIL UJI RELIABILITAS

\begin{tabular}{ccc}
\hline Dimensi & Hasil Uji Reliabilitas & Keterangan \\
\hline Empati & 0,832 & Reliabel \\
\hline Persuasi & 0,893 & Reliable \\
\hline Dampak & 0,898 & Reliable \\
\hline Komunikasi & 0,665 & Cukup reliabel \\
\hline
\end{tabular}

Dapat dilihat dari tabel diatas bahwa semua dimensi telah lulus uji reliabilitas dengan rentang cukup reliabel hingga reliabel. Maka dapat dikatakan bahwa seluruh instrument memiliki konsistensi dan aurasi yang baik.

\section{Efektivitas Iklan Dimensi EPIC}

Terlebih dahulu akan dicari rentang skala untuk menentukan apakah iklan tersebut efektif atau tidak, dengan rumus (Purwanto, Ade dan umam, 2019):

$$
R s=\frac{5-1}{5}=0,8
$$

Sehingga dapat diperoleh skala sebagai berikut: 


\section{Tabel 6. \\ SKALA KEPUTUSAN EPIC MODEL}

\begin{tabular}{cc}
\hline Rentang Skala & Kriteria Keputusan \\
\hline $1-1,80$ & sangat tidak efektif \\
\hline $1,81-2,60$ & tidak efektif \\
\hline $2,61-3,40$ & cukup efektif \\
\hline $3,41-4,20$ & efektif \\
\hline $4,21-5$ & sangat efektif \\
\hline
\end{tabular}

1. Dimensi Empati

Dimensi empati memiliki 3 indikator yaitu kognisi, afeksi, dan ketertarikan terhadap iklan. Hasil dari tiap indikator adalah:

a. Hasil Indikator kognisi akan dicari berdasarkan dari hasil tabulasi jawaban responden sebagai berikut:

$$
\frac{4,05+4+2,9}{3}=3,65
$$

b. Hasil Indikator afeksi akan dicari berdasarkan dari hasil tabulasi jawaban responden sebagai berikut:

$$
\frac{4,01+4,07+3,77}{3}=3,95
$$

c. Hasil Indikator ketertarikan terhadap iklan akan dicari berdasarkan dari hasil tabulasi jawaban responden sebagai berikut:

$$
\frac{4,01+3,52+4}{3}=3,84
$$

Dengan hasil dari ketiga indikator diatas akan dicari nilai rata-rata untuk menghitung hasil dimensi empati, yaitu:

$$
\text { Dimensi Empati }=\frac{3,65+3,95+3,84}{3}=3,81
$$

Hasil tersebut menunjukan bahwa nilai rata-rata 3,81 yang dimana dimensi empati termasuk ke dalam kategori iklan efektif. Pengerauh kognisi dan afeksi dari iklan dapat membuat konsumen untuk menyukai atau tertarik terhadap iklan yang ditampilkan. 


\section{Dimensi Persuasi}

Dimensi persuasi memiliki 2 indikator yaitu indicator perubahan sikap dan perubahan perilaku konsumen. Hasil tiap indikator adalah:

a. Hasil indikator perubahan sikap akan dicari berdasarkan hasil tabulasi jawaban responden, sebagai berikut:

$$
\frac{3,81+4,17+4,31}{3}=4,09
$$

b. Hasil indikator perubahan perilaku akan dicari berdasarkan hasil tabulasi jawaban responden, sebagai berikut:

$$
\frac{4,31+3,92+3,8}{3}=4,01
$$

Dengan hasil dari kedua indikator diatas akan dicari nilai rata-rata untuk menghitung hasil dimensi persuasi, yaitu:

$$
\text { Dimensi Persuasi }=\frac{4,09+4,01}{2}=4,05
$$

Hasil tersebut menunjukan bahwa nilai rata-rata dimensi persuasi sebesar 4,05 termasuk ke dalam kategori iklan efektif. Hal ini menunjukan bahwa ikla Gojek dapat memengaruhi perilaku dan sifat konsumen dalam mangambil keputusan pembelian.

3. Dimensi Dampak

Dimensi dampak memiliki 3 indikator yaitu indicator repitisi, kesan, dan keunikan iklan. Berikut hasil dari setiap indikator:

a. Hasil dari indikator repitisi akan dicari berdasarkan tabulasi jawaban dari responden yang telah menjawab, Hasilnya adalah:

$$
\frac{3,7+3,97+3,02}{3}=3,56
$$

b. Hasil dari indikator kesan yang ditinggal iklan kepada konsumen akan dicari berdasarkan tabulasi jawaban dari responden yang telah menjawab, Hasilnya adalah:

$$
\frac{3,72+3,92+3,99}{3}=3,87
$$


c. Hasil dari indikator keunikan iklan akan dicari berdasarkan tabulasi jawaban dari responden yang telah menjawab, Hasilnya adalah:

$$
\frac{3,3+4,13+4,02}{3}=3,81
$$

Dengan hasil dari setiap indikator dimensi dampak yang telah dihitung sebelumnya, maka akan dicari nilai rata-rata untuk mengetahui hasil dari dimensi dampak, yaitu:

$$
\text { Dimensi Dampak }=\frac{3,56+3,87+3,81}{3}=3,74
$$

Berdasarkan dari hasil perhitung diatas, dapat diketahui bahwa dimensi dampak memiliki nilai rata-rata sebesar 3,74 termasuk ke dalam kategori skala iklan efektif. Hal ini menunjukan bahwa iklan Gojek yang unik dapat membuat konsumen untuk lebih tertarik melihat iklan kembali sehingga dapat memberikan kesan yang baik kepada konsumen.

4. Dimensi Komunikasi

Dimensi komunikasi memiliki 2 indikator yaitu indicator kemampuan mengingat dan pemanahan dari konsumen atas iklan yang ditayangkan. Berikut hasil dari setiap indikator:

a. Hasil dari indikator kemampuan mengingat konsumen akan dicari berdasarkan hasil tabulasi jawaban dari responden yang telah menjawab, Hasilnya adalah:

$$
\frac{4,36+3,81+4,08}{3}=4,08
$$

b. Hasil dari indikator kemampuan pemahaman konsumen terhadap akan dicari berdasarkan hasil tabulasi jawaban dari responden yang telah menjawab, Hasilnya adalah:

$$
\frac{4,08+4,09+4,26}{3}=4,14
$$

Dengan telah diketahuinya hasil dari setiap indikator dimensi komunikasi, maka selanjutnya akan dicari nilai rata-rata untuk mengetahui nilai dari dimensi komunikasi, sebagai berikut: 


$$
\text { Dimensi Komunikasi }=\frac{4,08+4,14}{2}=4,11
$$

Berdasarkan hasil yang telah dihitung diatas dapat diketahui bahwa dimensi komunikasi memiliki nilai rata-rata sebesar 4,11 yang termasuk ke dalam skala kategori iklan efektif. Dapat diindikasikan bahwa iklan Gojek dapat dengan baik untuk diingat dan dimengerti oleh konsumen yang melihatnya.

5. Hasil Analisis EPIC

Berdasarkan dari perhitung keempat dimensi EPIC diatas dapat diketahui bahwa nilai dari masing-masing dimensi sebagai berikut:

Tabel 7.

HASIL EPIC MODEL

\begin{tabular}{ccc}
\hline EPIC & Nilai & Kategori \\
\hline Empati & 3,81 & Efektif \\
\hline Persuasi & 4,05 & Efektif \\
\hline Dampak & 3,74 & Efektif \\
\hline Komunikasi & 4,11 & Efektif \\
\hline
\end{tabular}

Dimensi empati memiliki nilai rata-rata sebesar 3,81, dimensi persuasi memiliki nilai rata-rata sebesar 4,05, dimensi dampak memiliki nilai rata-rata sebesar 3,74, dan dimensi komunikasi memiliki nilai rata-rata sebesar 4,11. Sehingga dari hasil tabel diatas dapat dihitung nilai rata-rata dari total hasil keempat dimensi untuk mengetahui hasil analisis EPIC iklan online Gojek, yaitu:

$$
\text { Epic Rate }=\frac{3,81+4,05+3,74+4,11}{4}=3,93
$$

Yang jika dimasukan ke dalam skala efektivitas iklan hasilnya akan menjadi seperti ini:

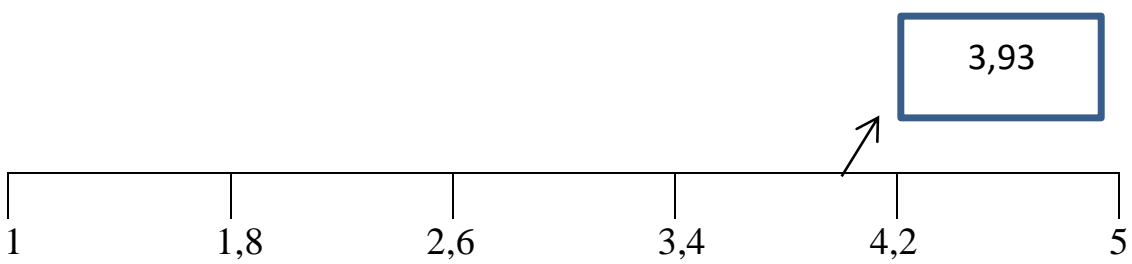


Nilai EPIC Rate dari hasil perhitungan sebelumnya diperoleh hasil 3,93, hasil tersebut masuk kedalam kategori iklan efektif yang dapat dilihat bahwa hasil EPIC Rate berada diantara rentang nilai 3,4 (cukup efektif) dan 4,2 (efektif).

\section{SIMPULAN}

Berdasarkan hasil penelitian yang telah dikerjakan sebelumnya, dengan mencari nilai rata-rata setiap dimensi, dapat diketahui bahwa dimensi komunikasi memiliki nilai tersebsar yaitu 4,11, lalu dimensi persuasi dengan nilai 4,05, dimensi empati dengan nilai 3,81, dan dimensi dampak dengan nilai 3,74. Dapat dilihat bahwa dimensi komunikasi memiliki nilai rata-rata terbesar yang dapat diartikan bahwa iklan Gojek dapat mudah diingat dan dipahami oleh konsumen. Dimensi persuasi dapat memengaruhi sifat serta keputusan konsumen mengenai iklan yang telah mereka lihat, yaitu apakah mereka ingin menggunakan layanan Gojek atau tidak. Dimensi empati dapat memberikan informasi yang baik kepada konsumen sehingga dengan informasi yang telah diberikan kepada konsumen dapat membentuk persepsi konsumen terhadap iklan serta menyukai iklan. Dimensi dampak dapat memberikan dapat yang baik kepada pelanggan serta perusahaan yaitu dengan adanya repetisi yang dilakukan konsumen. Lalu mencari EPIC Rate dari iklan online Gojek hasil menunjukan bahwa EPIC Rate iklan online Gojek adalah sebesar 3,93 yang termasuk dalam kategori iklan efektif.

\section{DAFTAR PUSTAKA}

Amira, N., \& Nurhayati, I. K. (2019). Efektivitas Fitur Instagram Sponsored sebagai Media Iklan/Promosi (Studi pada Iklan Tiket.com dengan Metode EPIC Model). Journal Of Media and Communication Science, 2(2), 116-126.

Aryanto, A. (2019). Iklan Go-Jek Cari Kebaikan Menangkan Penghargaan Most Loved. Republika. Retrieved from https://www.republika.co.id/berita/purhhb/iklan-gojek-cari-kebaikanmenangkan-penghargaan-most-loved

Bestriandita, D., \& Widodo, E. (2017). Analisis Perbandingan Efektivitas Iklan Menggunakan EPIC Model Terhadap Mahasiswa UII Yogyakarta. Prosiding Seminar Nasional Integrasi Matematika Dan Nilai Islami, 1(1), 214-220.

Burhan, F. A. (2020, November 12). Transaksi Gojek Tumbuh $10 \%$ \& Gopay Naik 2 Kali Lipat di Masa Pandemi. Katadata. Retrieved from 
https://katadata.co.id/yuliawati/digital/5fad26a3c2db7/transaksi-gojektumbuh-10-gopay-naik-2-kali-lipat-di-masa-pandemi

Erminati Pancaningrum, \& Wahyu Ari Rahayu. (2017). The Effectiveness of Facebook as an Advertising Strategic Method Using EPIC: A Case Study of Mie Jupe Jombang. Chinese Business Review, 16(7), 309-315. https://doi.org/10.17265/1537-1506/2017.07.001

Gisrang, L. R. (2017). Pengukuran Efektivitas Iklan (Studi Komparasi: Iklan Media Cetak Dan Iklan Media Online). Expert Review of Anticancer Therapy, 17(11), https://doi.org/10.1080/14737140.2017.1380521

Gojek.com (2020). J3K cara hidup nyaman pakai Gojek. (https://www.gojek.com/j3k/ Diakses pada 12 Maret 2021)

Gunawan, L. (2015). Efektivitas Iklan Televisi Suzuki Karimun Wagon R di Masyarakat Surabaya. Pneumologie, 2(3), 537.

Indah, D. R., \& Maulida, Z. (2017). Analisis Efektifitas Iklan Media Televisi Menggunakan EPIC Model ( Studi Kasus Produk A Mild di Kota Langsa ). Penelitian Ekonomi Akuntansi, 1(2), 137-149.

IndoTelko. (2019). Survei:Konsumen lebih aman gunakan Gojek dibanding Grab. IndoTelko. Retrieved from https://www.indotelko.com/read/1564547336/konsumen-gojekgrab\#: :text=Dua brand jasa transportasi online,dan yang memanfaatkan keduanya mencapai

Indrawati, K. A. P., Sudiarta, N. I., \& Suardana, W. I. (2017). Efektivitas Iklan Melalui Media Sosial Facebook Dan Instagram Sebagai Salah Satu Strategi Pemasaran Di Krisna Oleh-Oleh Khas Bali. Analisis Pariwisata, 17(2), 78-83. Retrieved from https://ojs.unud.ac.id/index.php/jap/article/view/36484

Ludwianto, B. (2020, November 12). 10 Tahun Gojek: 38 Juta Pengguna Aktif Bulanan Hingga Cetak Laba. Kumparan. Retrieved from https://kumparan.com/kumparantech/10-tahun-gojek-38-juta-penggunaaktif-bulanan-hingga-cetak-laba-1uZiKid82Mo/full 
Pancaningrum, E., \& Sari, D. K. (2019). Analisa Epic Model: Mengukur Efektivitas Iklan Indomie Versi Ayam Geprek Di Televisi. JAD: Jurnal Manajemen Dan Bisnis Dewantara, 2(1), 53-61.

Purwanto, Ade dan umam, K. (2019). The Effectiveness Of Tagline "Ada Aqua" Using EPIC Model In Rangkapan Jaya Baru Sub-Disttic Pancoran Depok. 2(2), 199-209.

Putra, A. N., Noviyanto, I., \& Christover, A. P. (2018). Analysis the Effectiveness Instagram Advertising of Steeze's Clothing Product Using Epic Model and Influence on Consumers Buying Interest. International Journal of Innovative Science and Research Technology, $3(11)$.

Putro, S. A. (2017). STRATEGI KOMUNIKASI PEMASARAN VIDEOGRAFI CV. USER MEDIA KARANGANYAR MELALUI MARKETING MIX. Journal of Chemical Information and Modeling, 8(9), 16-17. https://doi.org/10.1017/CBO9781107415324.004

Reyes, W., Serafico, N. M., Hendrayati, H., \& Ramdhan, A. (2019). Analysis of the Effectiveness of Promoted Listings Using the Method of EPIC Model. 65(Icebef 2018), 93-95. https://doi.org/10.2991/icebef18.2019.22

Santoso, yusuf imam. (2020). Sri Mulyani: Ekonomi Indonesia pada tahun 2020 berlangsung dramatis akibat pandemi. Kontan.Co.Id. Retrieved from https://nasional.kontan.co.id/news/sri-mulyani-ekonomiindonesia-pada-tahun-2020-berlangsung-dramatis-akibat-pandemi

Sastika, W. (2018). Epic Model: Pengukuran Efektivitas Iklan Kuliner Melalui Sosial Media Instagram @Kulinerbandung Sebagai Media Promosi. JTIM - Jurnal Teknologi Informasi \& Manajemen, l(01), 21. https://doi.org/10.25124/jtim.v1i01.1531

Sugiyono. (2016). Metode Penelitian Kuantitatif, Kualitatif dan $R \& D$. Bandung: PT Alfabet. 